\title{
The Predictive Value of Mean Platelet Volume for Liver Fibrosis in Children With Chronic Liver Diseases
}

\author{
Seyed Mohsen Dehghani ${ }^{10}$, Mohammad Reza Bordbar ${ }^{1}$, Rezvan Salimi ${ }^{1}$, Iraj Shahramian², Hadi Mirzae ${ }^{3}$, \\ Siavash Gholami' ${ }^{1}$, Fatemeh Sharafi ${ }^{4}$, Ali Bazi ${ }^{2 *}{ }^{\mathbb{D}}$, Maryam Ataollahi $^{1}$, Fatemeh Fazeli ${ }^{1}$, Samaneh Hamzeloo ${ }^{1}$ \\ ${ }^{1}$ Professor of Pediatrics Gastroenterology, School of Medicine, Shiraz University of Medical Sciences, Shiraz, Iran \\ ${ }^{2}$ Pediatric Gastroenterology and Hepatology Research Center, Zabol University of Medical Sciences, Zabol, Iran \\ ${ }^{3}$ Department of Biotechnology, Faculty of Medicine, Zabol University of Medical Sciences, Zabol, Iran \\ ${ }^{4}$ Internal Medicine Department, Faculty of Medicine, Mashhad University of Medical Sciences, Mashhad, Iran
}

*Correspondence to Ali Bazi,

Tel/fax: + 985432232166 , Email: m.baziali@gmail.com

Received December 6, 2020 Accepted December 26, 2020 Published online December 30, 2020

\begin{abstract}
Introduction: Almost all causes of chronic liver damage can culminate in liver fibrosis and ultimately cirrhosis. Studies have suggested a relationship between mean platelet volume (MPV) and liver fibrosis; however, this needs confirmation by further studies. We here assessed the predictive value of MPV for liver fibrosis in children with chronic liver diseases.

Methods: In this study, children $<18$ years old with chronic liver diseases referred to the Nemazee Hospital of Shiraz during 2013-2016 were studied. The patients underwent liver biopsy for assessing liver fibrosis. Statistical analyses were conducted in SPSS 23.

Results: From 368 studied children, $52.2 \%$ were boys. The patients' mean age was $4.5 \pm 3.9$ years old. Most patients had grade 6 fibrosis $(36.7 \%)$. Cryptogenic $(42.7 \%)$ was the most common cause of chronic liver disease, and jaundice was the most prevalent clinical presentation (53\%). There was a significant association between the liver fibrosis and MPV $(P=0.025)$.

Conclusion: MPV was significantly different between patients with different severities of liver fibrosis. However, assigning an appropriate cut off value to distinguish different degrees of fibrosis requires more studies.

Keywords: Chronic liver disease, Liver fibrosis, Mean platelet volume
\end{abstract}

\section{Introduction}

Mean platelet volume (MPV) is a marker of platelet size and function. ${ }^{1,2}$ The prognostic validity of MPV has been evaluated in various diseases. ${ }^{1}$ Elevated MPV has been associated with adverse prognosis in acute coronary syndrome and patients with cardiovascular diseases and deep veins thrombosis. In patients with non-alcoholic fatty liver disease, MPV values have been higher compared with healthy individuals. ${ }^{3}$ Furthermore, MPV has been suggested as an independent predictive marker for liver fibrosis and cirrhosis in patients with chronic hepatitis B virus and hepatitis C virus infections. ${ }^{4-6}$ In another studies, MPV values have been comparable in patients with different severities ${ }^{7}$ or etiologies ${ }^{8}$ of chronic liver disease. Overall, the role of MPV in children with chronic liver disease is unclear and inconclusive. In this study, we assessed predictive value of MPV for liver fibrosis in Iranian children with chronic liver diseases.

\section{Materials and Methods}

All children $<18$ years old diagnosed with chronic liver diseases and underwent liver biopsy in Nemazee teaching hospital affiliated with Shiraz University of Medical Sciences from 2013 to 2016 were included. Children who had not liver biopsy examination were excluded. Also, children diagnosed with concurrent: infectious diseases, chronic kidney disease, collagen vascular diseases, malignancies, and hemoglobinopathies were excluded.

All data was gathered using a checklist. The recorded information included patient's age, gender, underlying diseases,

(c) 2020 The Author(s); Published by Zabol University of Medical Sciences. This is an open-access article distributed under the terms of the Creative Commons Attribution License (http://creativecommons.org/licenses/by/4.0), which permits unrestricted use, distribution, and reproduction in any medium, provided the original work is properly cited. 
presenting clinical symptoms, results of laboratory tests (serum albumin, bilirubin, liver enzymes, sodium, INR creatinine, white blood cells and platelets counts, red cell distribution width and MPV, MELD/PELD (model for end-stage liver disease/pediatric end-stage liver disease) scores, Child-Pugh score, and results of liver biopsy. In addition, non-invasive fibrosis markers (AAR, APRI, and FIB-4) were calculated. These data were recorded using patients' medical archives.

The data were analyzed by SPSS version 23 using descriptive and analytical statistics. Kruskal-Wallis test, Spearman correlation, and ROC curve analysis were used.

\section{Results}

In this study, 368 patients with chronic liver diseases who had been undergone liver biopsy were assessed. From these, 192 (52.2\%) and 176 (47.8\%) were males and females, respectively. The mean age of the patients in this study was $4.5 \pm 3.9$ years old.

Considering the underlying diseases, 84 (22.8\%) of patients had biliary atresia as the second most common reason after unknown causes (Table 1). The most common presenting clinical symptom was jaundice $(n=195 ; 53 \%)$. Table 2 demonstrates clinical symptoms of the patients. A summary on laboratory features of the patients has been demonstrated in Table 3. Most of the patients revealed severe fibrosis with grades $5(n=33 ; 9 \%)$ and $6(n=135$; $36.7 \%$ ) (Table 4). There were no association between the severity of fibrosis with underlying causes of liver disease (Table 5).

The average Child-Pugh score was $6.86 \pm 1.63$ and 138 (37.5\%), 185 (50.3\%), and 21 (5.7\%) of children were in classes $\mathrm{A}, \mathrm{B}$, and $\mathrm{C}$, respectively. The average MELD/ PELD (model for end-stage liver disease/pediatric endstage liver disease) score in patients was $4.6 \pm 11.3$ (range of 12 to 67). Mean values of MPV, AAR, APRI, and FIB4 were $10.59 \pm 1.9,1.54 \pm 0.90,4.80 \pm 12.77$, and $0.47 \pm 1.37$, respectively. According to our findings, MPV was no significantly associated with the grade of fibrosis (Table 6, $P=0.144)$.

Table 1. Distribution of Underlying Causes in Patients With Chronic Liver Disease

\begin{tabular}{lcc}
\hline Underlying Diseases & No. & Percent \\
\hline Unknown & 157 & 42.7 \\
Biliary atresia & 84 & 22.8 \\
PFIC & 30 & 8.2 \\
Neonatal hepatitis & 32 & 8.7 \\
Auto immune hepatitis & 14 & 3.8 \\
Wilson disease & 9 & 2.4 \\
Tyrosinemia & 17 & 4.6 \\
Glycogen storage disease & 12 & 3.3 \\
Other metabolic disorders & 13 & 3.5 \\
\hline
\end{tabular}

PFIC, Progressive familial intrahepatic cholestasis
Table 2. Clinical Symptoms of Patients

\begin{tabular}{lcc}
\hline Clinical Manifestation & Number & Percent \\
\hline Jaundice & 195 & 53 \\
Hepatomegaly & 84 & 22.8 \\
Splenomegaly & 70 & 19 \\
Pruritus & 44 & 12 \\
Ascites & 27 & 7.3 \\
Gl bleeding & 16 & 4.3 \\
Encephalopathy & 6 & 1.6 \\
Spontaneous bacterial peritonitis & 3 & 0.8 \\
\hline
\end{tabular}

Table 3. Laboratory Tests Results in Children With Chronic Liver Disease

\begin{tabular}{lc}
\hline Laboratory Parameters & Mean Values (Minimum-Maximum) \\
\hline Aspartate aminotransferase $(\mathrm{IU} / \mathrm{L})$ & $297.16 \pm 421.9(4-4700)$ \\
Alanine aminotransferase $(\mathrm{IU} / \mathrm{L})$ & $236.08 \pm 336.6(9-3604)$ \\
Total bilirubin $(\mathrm{mg} / \mathrm{dL})$ & $6.13 \pm 7.97(0-65.2)$ \\
Albumin $(\mathrm{g} / \mathrm{dL})$ & $4.04 \pm 0.65(0-6.6)$ \\
Creatinine $(\mathrm{mg} / \mathrm{dL})$ & $0.38 \pm 0.25(0.1-1.8)$ \\
Na (mEq/L) & $138.94 \pm 8.14(14-153)$ \\
International normalized ratio & $1.53 \pm 1.14(1-14) 1$ \\
White blood cell count $\left(10^{3} / \mu \mathrm{L}\right)$ & $10398 \pm 5468.6(2700-68100)$ \\
Hemoglobin $(\mathrm{g} / \mathrm{dL})$ & $10.64 \pm 1.88(5.1-18)$ \\
Mean corpuscular volume $(\mathrm{fl})$ & $83.26 \pm 8.76(56.2-111)$ \\
Red cell distribution width $(\mathrm{fl})$ & $16.73 \pm 5.95(0-71.5)$ \\
Platelet count $\left(10^{3} / \mu \mathrm{L}\right)$ & $305140 \pm 173.8(27-1166)$ \\
Mean platelet volume $(\mathrm{fl})$ & $10.59 \pm 1.90(7-23.9)$ \\
\hline
\end{tabular}

Table 4. Fibrosis Severity in Children With Chronic Liver Disease

\begin{tabular}{lccc}
\hline Stage of Fibrosis & & Number & Percent \\
\hline \multirow{3}{*}{ Mild } & 46 & 0 & 12.5 \\
& 47 & 1 & 12.8 \\
\multirow{2}{*}{ Moderate } & 22 & 2 & 6.0 \\
& 69 & 3 & 18.8 \\
Severe & 16 & 4 & 4.3 \\
Total & 33 & 5 & 9.0 \\
\hline
\end{tabular}

Considering the severity of liver fibrosis values based on the underlying disease, MPV showed significant difference only in patients with neonatal hepatitis $(P=0.020)$ (Table 7). Statistically significant difference was found between MPV values in children with different Child score $(P=0.002)$.

There was no significant statistical difference between AAR (AST/ALT ratio) and the grade of fibrosis $(P>0.05)$. However, APRI was significantly correlated with the severity of liver fibrosis $(P<0.001)$. The FIB-4 was significantly associated with fibrosis grade $(P<0.001)$ and 
Table 5. Distribution of Underlying Diseases Based on the Severity of Liver Fibrosis in Children With Chronic Liver Diseases

\begin{tabular}{lccc}
\hline \multirow{2}{*}{ Underlying Causes } & \multicolumn{3}{c}{ Severity of Liver Fibrosis } \\
\cline { 2 - 4 } & Mild (\%) & Moderate (\%) & Severe (\%) \\
\hline Biliary atresia & $15(17.9)$ & $32(38.1)$ & $37(44)$ \\
PFIC & $4(13.3)$ & $9(30)$ & $17(56.7)$ \\
Neonatal hepatitis & $25(78.1)$ & $4(12.5)$ & $3(9.4)$ \\
Auto immune hepatitis & $7(50)$ & $2(14.3)$ & $5(35.7)$ \\
Wilson disease & $1(11.1)$ & $0(0)$ & $8(88.9)$ \\
Tyrosinemia & $1(5.9)$ & $0(0)$ & $16(94.1)$ \\
Glycogen storage disease & $3(25)$ & $3(25)$ & $6(50$ \\
Other metabolic disorders & $3(23.1)$ & $3(23.1)$ & $7(53.8)$ \\
\hline PFIC, Progressive familial int
\end{tabular}

PFIC, Progressive familial intrahepatic cholestasis.

Table 6. Values of MPV, AAR, APRI, and FIB-4 in Various Grades of Liver Fibrosis

\begin{tabular}{|c|c|c|c|c|c|c|}
\hline \multicolumn{2}{|c|}{ Stage of Fibrosis } & \multirow{2}{*}{$\begin{array}{c}\text { Frequency } \\
46\end{array}$} & \multirow{2}{*}{$\begin{array}{c}\text { Minimum } \\
7.8\end{array}$} & \multirow{2}{*}{$\begin{array}{c}\text { Maximum } \\
13.3\end{array}$} & \multirow{2}{*}{$\begin{array}{l}\text { Mean } \\
10.26\end{array}$} & \multirow{2}{*}{$\begin{array}{c}\begin{array}{c}\text { Standard } \\
\text { Deviation }\end{array} \\
1.28\end{array}$} \\
\hline \multirow{4}{*}{0} & MPV & & & & & \\
\hline & AAR & 46 & 0.34 & 4.76 & 1.61 & 0.96 \\
\hline & APRI & 46 & 0.16 & 31.15 & 2.09 & 4.76 \\
\hline & FIB-4 & 46 & 0.02 & 1.72 & 0.19 & 0.37 \\
\hline \multirow{4}{*}{1} & MPV & 47 & 7.9 & 23.9 & 10.88 & 2.80 \\
\hline & AAR & 46 & 0.18 & 3.13 & 1.45 & 0.66 \\
\hline & APRI & 46 & 0.18 & 23.11 & 2.55 & 4.55 \\
\hline & FIB. 4 & 46 & 0.01 & 1.38 & 0.16 & 0.24 \\
\hline \multirow{4}{*}{2} & MPV & 22 & 7.0 & 11.5 & 9.89 & 1.19 \\
\hline & AAR & 22 & 0.42 & 4.86 & 1.52 & 0.97 \\
\hline & APRI & 22 & 0.07 & 22.22 & 3.19 & 4.91 \\
\hline & FIB. 4 & 22 & 0.01 & 2.69 & 0.42 & 0.77 \\
\hline \multirow{4}{*}{3} & MPV & 69 & 7.6 & 17.6 & 10.51 & 1.87 \\
\hline & AAR & 68 & 0.04 & 7.00 & 1.41 & 0.94 \\
\hline & APRI & 68 & 0.03 & 14.63 & 2.27 & 2.74 \\
\hline & FIB. 4 & 68 & 0.00 & 2.57 & 0.17 & 0.38 \\
\hline \multirow{4}{*}{4} & MPV & 16 & 8.6 & 11.9 & 10.05 & 1.11 \\
\hline & AAR & 16 & 0.32 & 4.08 & 1.71 & 0.97 \\
\hline & APRI & 16 & 0.27 & 19.66 & 2.61 & 4.62 \\
\hline & FIB. 4 & 16 & 0.01 & 1.24 & 0.12 & 0.29 \\
\hline \multirow{4}{*}{5} & MPV & 33 & 8.3 & 16.1 & 11.08 & 1.99 \\
\hline & AAR & 33 & 0.27 & 3.79 & 1.81 & 0.92 \\
\hline & APRI & 33 & 0.54 & 6.22 & 2.22 & 1.53 \\
\hline & FIB. 4 & 33 & 0.02 & 2.98 & 0.22 & 0.51 \\
\hline \multirow{4}{*}{6} & MPV & 135 & 7.2 & 19.8 & 10.77 & 1.88 \\
\hline & AAR & 127 & 0.36 & 6.61 & 1.56 & 0.91 \\
\hline & APRI & 127 & 0.06 & 137.93 & 8.36 & 19.39 \\
\hline & FIB. 4 & 127 & 0.02 & 19.02 & 0.88 & 2.12 \\
\hline
\end{tabular}

severity $(P<0.001)$

According to ROC curve analysis, the 10.4 cut off values of MPV to predict severe fibrosis (Stage $\geq 5$ ) rendered AUC (area under the ROC curve) $=0.582$, with the sensitivity and specificity of $52.4 \%$ and $65 \%$, respectively (Figure 1A). Also, the optima cut off value for diagnosis of moderate and severe fibrosis (Stage $\geq 3$ ) was obtained MPV $\geq 3$ to 10.9 with $\mathrm{AUC}=0.548$ and sensitivity of $34.8 \%$ and specificity of $74.8 \%$ (Figure $1 \mathrm{~B}$ ). The cut off MPV for detecting any fibrosis was obtained $>10.8$ with AUC $=0.544$, sensitivity of $35.7 \%$ and specificity of $76.1 \%$ (Figure 1C).

\section{Discussion}

In this study, 368 patients with chronic liver diseases who had been undergone liver biopsy were surveyed. The most common causes of chronic liver disease were cryptogenic, biliary atresia, neonatal hepatitis, progressive familial intrahepatic cholestasis (PFIC), tyrosinemia with 157 (42.7\%), 84 (22.8\%), 32 (8.7\%), 30 (8.2\%), and 17 (4.6\%), respective frequencies. The most common clinical sign was jaundice $(53 \%)$. Most patients $(n=135 ; 36.7 \%)$ had Ishak fibrosis degree of 6 (i.e. cirrhosis). There was no association between MPV and fibrosis grade (S0 to S6) $(P=0.144)$. The average MPVs in patients with mild, moderate, and severe fibrosis were $10.45 \pm 2.06,10.42 \pm 1.76$ and $10.83 \pm 1.90$, respectively $(P=0.025)$. Also, considering underlying diseases, significant relationship with liver fibrosis severity and MPV was only observed in patients with neonatal hepatitis (MPV $=10.64 \pm 1.15$ vs. $8.4 \pm 0.40$ in mild $(\mathrm{n}=25)$ and severe fibrosis $(\mathrm{n}=3)(P=0.02)$.

The results of ROC curve analysis showed that MPV cut off point of 10.4 rendered $\mathrm{AUC}=0.582$ and sensitivity and specificity of $52.4 \%$ and $65 \%$ for differentiating severe fibrosis $(S \geq 5)$ than other stages $(S<5)$. For differentiating
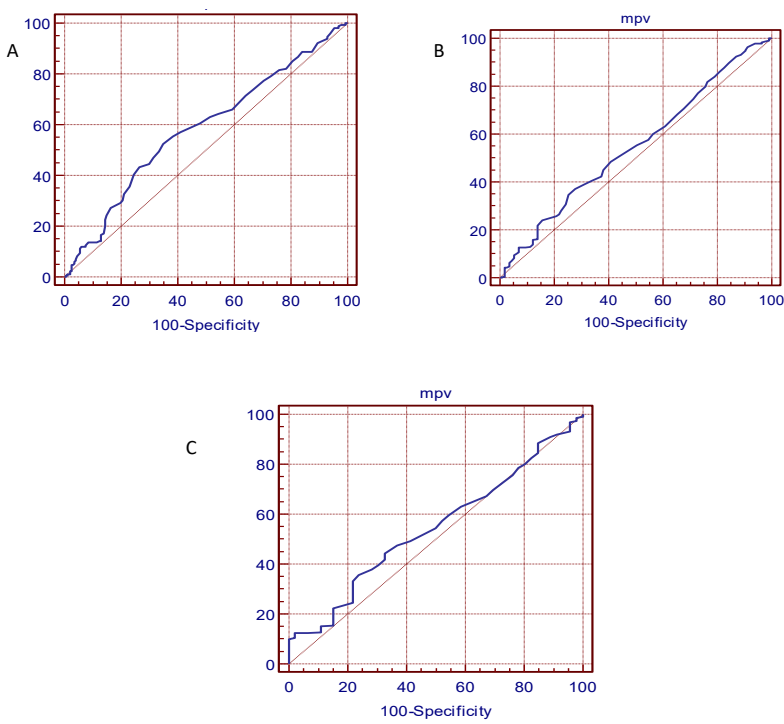

Figure 1. ROC Curve Analysis for Mean Platelet Volume. (A) fibrosis grade $\geq 5$, (B) fibrosis grade $\geq 3$, (C) any fibrosis. 
Table 7. Values of MPV, AAR, APRI, and FIB-4 in Various Severities of Liver Fibrosis

\begin{tabular}{|c|c|c|c|c|c|c|}
\hline & & Frequency & Minimum & Maximum & Mean & Standard Deviation \\
\hline \multirow{4}{*}{ Mild } & MPV & 115 & 7.0 & 23.9 & 10.45 & 2.06 \\
\hline & AAR & 114 & 0.18 & 4.86 & 1.53 & 0.85 \\
\hline & APRI & 114 & 0.07 & 31.15 & 2.49 & 4.68 \\
\hline & FIB. 4 & 114 & 0.01 & 2.69 & 0.22 & 0.44 \\
\hline \multirow{4}{*}{ Moderate } & MPV & 85 & 7.6 & 17.6 & 10.42 & 1.76 \\
\hline & AAR & 84 & 0.04 & 7.00 & 1.47 & 0.95 \\
\hline & APRI & 84 & 0.03 & 19.66 & 2.34 & 3.15 \\
\hline & FIB. 4 & 84 & 0.00 & 2.57 & 0.16 & 0.36 \\
\hline \multirow{4}{*}{ Severe } & MPV & 168 & 7.2 & 19.8 & 10.83 & 1.90 \\
\hline & AAR & 160 & 0.27 & 6.61 & 1.61 & 0.92 \\
\hline & APRI & 160 & 0.06 & 137.93 & 7.09 & 17.45 \\
\hline & FIB. 4 & 160 & 0.02 & 19.02 & 0.75 & 1.92 \\
\hline
\end{tabular}

moderate and severe fibrosis $(\mathrm{S} \geq 3)$ from mild fibrosis, the cut off of 10.9 delivered $\mathrm{AUC}=0.548$ and sensitivity and specificity of $34.8 \%$ and $74.8 \%$, respectively. Finally, the cut off MPV value of 10.8 delivered AUC $=0.544$, sensitivity of $35.7 \%$ and specificity of $76.1 \%$ for detecting any stage of fibrosis $(\mathrm{S} \geq 1)$ from no fibrosis ( $\mathrm{S} 0$ ). These results show that MPV is not a good marker for predicting liver fibrosis. MPV had no significant association with neither age nor underlying diseases.

In reviewing other markers of liver fibrosis, no significant difference was found in AAR among different severities of liver fibrosis $(P>0.05)$. However, APRI was significantly different among various stages of liver fibrosis $(\mathrm{S} 0=2.09, \mathrm{~S} 1=2.55, \mathrm{~S} 3=2.27, \mathrm{~S} 6=8.36, P<0.001)$. Also, APRI was significantly different among patients with different severities of liver fibrosis (mild, moderate and severe) with $P<0.001$ that the difference between the mild fibrosis (mild=2.49, moderate $=2.34$, and severe $=7.09, P=0.001)$. Therefore, APRI can be used as a marker to predict the severity of liver fibrosis, especially for differentiating mild from severe fibrosis.

Also, FIB-4 index was significantly different among children with various degrees of fibrosis $(P<0.001)$. Mean FIB-4 values were $0.19,0.16,0.42,0.17,0.12,0.22$, and 0.88 for fibrosis stages 0 to 6 , respectively. For patients with mild, moderate and severe fibrosis, FIB- 4 values were as $0.22,0.16$, and 0.75 , respectively $(P<0.001)$. There were significant differences in FIB- 4 values between mild and moderate fibrosis in patients with PFIC (mild $=0.03$, moderate $=0.94 ; P=0.018$ ) and biliary atresia (mild $=0.09$, severe $=0.27, P<0.001$ ). Accordingly, FIB-4 index seems as an applicable marker to differentiate fibrosis severities, especially in patients with biliary atresia and PFIC.

The mean Child-Pugh score in our patients was $6.86 \pm 1.63$ and most of them belonged to class B (53.8\%). There was a significant difference in MPV comparing patients with Child class score A and B $(P=0.002)$. Also, the average MELD/PELD score in patients was
4.68 \pm 11.22 , and a significant relationship was detected between the MPV and MELD/PELD score $(P=0.022)$.

The most common causes of chronic liver disease in our study were cryptogenic and biliary atresia. In a study by Dehghani et al, most common causes of liver disease were biliary atresia and Wilson disease. ${ }^{9,10}$ In another study in Turkey, cryptogenic was the most common cause of cirrhosis which was in line with our report. ${ }^{8}$ The most common clinical symptom in our patients was jaundice which was in accordance to the previous study in Shiraz. ${ }^{9}$ 10

In this study, a significant difference was observed in MPV values regarding different fibrosis severities which was in parallel to the report of Tahtaci et al on PBC patients, ${ }^{11}$ Karagoz et al on patients with chronic hepatitis $B,{ }^{5}$ Purnak et al on patients with chronic hepatitis $\mathrm{C}^{6}{ }^{6}$ and Abdel-Razik et al on AIH patients. ${ }^{12}$ Furthermore, in our study only, MPV significantly differed in patients with neonatal hepatitis as well. There was no significant statistical relationship between MPV and age or underlying disease which was in line with the report of Giannini et al in Italy. ${ }^{7}$ In this study, there was no significant statistical differences between values and Child-Pugh score which was in oppose to the report of Giannini et al. in Italy, ${ }^{7}$ and Erdem et al in Turkey. ${ }^{8}$ No significant link was observed between MPV and MELD/ PELD score in our study which was different from the results Giannini et al in Italy, ${ }^{7}$ and $\mathrm{Hu}$ et al in China. ${ }^{13}$

According to the results of ROC curve analysis, an appropriate cut off did not obtained for MPV to differentiate various degrees of fibrosis. On the other hand, Tahtaci et al, ${ }^{11}$ Karagoz et $\mathrm{al}^{5}$ and Purnak et al ${ }^{6}$ reported threshold values with better predictability.

In this study, there was no significant statistical difference for AAR in various degrees of fibrosis which was in line with the study of Yang et al in China ${ }^{14}$ and Yang et al in South Korea. ${ }^{15}$ In this study, there was a statistically significant difference in APRI among different degrees 
of liver fibrosis which was supported by the reports of Tahtaci et al in Turkey, ${ }^{11}$ Kim et al in Japan, ${ }^{16}$ Yang et al in South Korea, ${ }^{15}$ Yang et al in China, ${ }^{14}$ and Shokouhi et al in Iran. ${ }^{17}$ FIB-4 index also showed a significant relationship with the degree of fibrosis in our study which was similar to the studies of Purnak et al in Turkey, ${ }^{6}$ Yang et al in South Korea, ${ }^{15}$ and Yang et al in China. ${ }^{14}$

\section{Conclusion}

In conclusion, although MPV was significantly associated with the severity of liver fibrosis, an optimal cut off point to distinguish different degrees fibrosis was not obtained. Therefore, MPV seems to not be a good marker for predicting fibrosis stage in children with cirrhosis.

\section{Ethical Approval}

This study was approved by the Ethics Committee in Research of Shiraz University of Medical Sciences (IR. SUMS.MED.REC.1399.122)

\section{Conflict of Interest Disclosure \\ None to declare.}

\section{Acknowledgments}

Thanks to the patients' families for their generous cooperation and Shiraz University of Medical Sciences for financial support.

\section{References}

1. Leader A, Pereg D, Lishner M. Are platelet volume indices of clinical use? a multidisciplinary review. Ann Med. 2012;44(8):805-816. doi:10.3109/07853890.2011.653391

2. Bath PM, Butterworth RJ. Platelet size: measurement, physiology and vascular disease. Blood Coagul Fibrinolysis. 1996;7(2):157-161.

3. Celikbilek M, Gürsoy S, Deniz K, Karaman A, Zararsiz G, Yurci A. Mean platelet volume in biopsy-proven nonalcoholic fatty liver disease. Platelets. 2013;24(3):194-199. doi:10.3109/09537104.2012.688898

4. Qi XT, Wan F, Lou Y, Ye B, Wu D. The mean platelet volume is a potential biomarker for cirrhosis in chronic hepatitis B virus infected patients. Hepatogastroenterology. 2014;61(130):456-459.

5. Karagoz E, Ulcay A, Tanoglu A, et al. Clinical usefulness of mean platelet volume and red blood cell distribution width to platelet ratio for predicting the severity of hepatic fibrosis in chronic hepatitis B virus patients. Eur J Gastroenterol Hepatol. 2014;26(12):1320-1324. doi:10.1097/meg.0000000000000203
6. Purnak T, Olmez S, Torun S, et al. Mean platelet volume is increased in chronic hepatitis $\mathrm{C}$ patients with advanced fibrosis. Clin Res Hepatol Gastroenterol. 2013;37(1):41-46. doi:10.1016/j.clinre.2012.03.035

7. Giannini EG, Moscatelli A, Brunacci M, Zentilin P, Savarino V. Prognostic role of mean platelet volume in patients with cirrhosis. Dig Liver Dis. 2016;48(4):409-413. doi:10.1016/j. dld.2015.10.018

8. Erdem MG, Çil EÖ, Tükek T, Helvacı ŞA. Evaluation of platelet and mean platelet volume levels in patients with liver cirrhosis. Archives of Clinical and Experimental Medicine. 2018;3(1):18-21. doi:10.25000/acem.390029

9. Dehghani SM, Imanieh MH, Haghighat M, Malekpour A, Falizkar Z. Etiology and complications of liver cirrhosis in children: report of a single center from southern Iran. Middle East J Dig Dis. 2013;5(1):41-46.

10. Dehghani SM, Shahramian I, Bazi A, Mohammadi Mofrad M, Mardani S. Evaluation of underlying liver disease and its severity in children referred for liver transplant: a singlecenter report from Nemazee hospital of Shiraz. Exp Clin Transplant. 2020;18(7):803-807. doi:10.6002/ect.2018.0047

11. TahtaciM,YurekliOT,Bolat AD, etal.Increased mean platelet volume is related to histologic severity of primary biliary cirrhosis. Eur J Gastroenterol Hepatol. 2015;27(12):13821385. doi:10.1097/meg.0000000000000463

12. Abdel-Razik A, Mousa N, Zakaria S, et al. New predictive factors of poor response to therapy in autoimmune hepatitis: role of mean platelet volume. Eur J Gastroenterol Hepatol. 2017;29(12):1373-1379. doi:10.1097/ meg.0000000000000982

13. Hu Y, Lou Y, Chen Y, Mao W. Evaluation of mean platelet volume in patients with hepatitis B virus infection. Int J Clin Exp Med. 2014;7(11):4207-4213.

14. Yang XZ, Gen AW, Xian JC, Xiao L. Diagnostic value of various noninvasive indexes in the diagnosis of chronic hepatic fibrosis. Eur Rev Med Pharmacol Sci. 2018;22(2):479-485. doi:10.26355/eurrev_201801_14198

15. Yang HR, Kim HR, Kim MJ, Ko JS, Seo JK. Noninvasive parameters and hepatic fibrosis scores in children with nonalcoholic fatty liver disease. World J Gastroenterol. 2012;18(13):1525-1530. doi:10.3748/wjg.v18.i13.1525

16. Kim SY, Seok JY, Han SJ, Koh H. Assessment of liver fibrosis and cirrhosis by aspartate aminotransferase-toplatelet ratio index in children with biliary atresia. J Pediatr Gastroenterol Nutr. 2010;51(2):198-202. doi:10.1097/ MPG.0b013e3181da1d98

17. Shokouhi S, Rakhshan M, Gachkar L, Khalaj E. Correlation between staging of hepatic fibrosis and biochemical markers in patient with liver fibrosis. Pejouhandeh. 2008;13(2):89-97. [Persian]. 